\title{
Full informed consent: the most basic measure of protection against medical malpractice suits
}

\author{
Heezoo Kim \\ Department of Anesthesiology and Pain Medicine, Korea University Guro Hospital, Korea University College of \\ Medicine, Seoul, Korea
}

The Shin Hae Chul Law, named after a famous Korean musician who passed away due to medical malpractice in 2014, went into practice on November 30, 2016 after approval by the National Assembly in May, 2016. The Shin Hae Chul Law, essentially, is aimed at implementing unconditional dispute mediation without participation or agreement on the part of the physician or medical institution when the patients and/or their families submit serious medical malpractice complaints to the Korea Medical Dispute Mediation and Arbitration Agency. Controversy has arisen over the enforcement of this law, in part, because it could result in passive and defensive medical practices.

One of the most basic and significant factors in medical malpractice lawsuits is full understanding and consent on the part of the patient and/or the family. By this law, physicians have become more responsible for the patients and their families to fully understand the information such as the current state (condition) of the patient, expectation of treatments, possible side effect or complications of procedures, since many medical malpractice suits are initiated due to lack of knowledge and/or mutual misunderstanding.

This month's issue of the Korean Journal of Anesthesiology included a study of legal disputes surrounding chronic pain management [1]. This paper presented cases that were submitted to the Legislation Committee of the Korean Society of Anesthesiology, all of which led to legal disputes over chronic pain treatment from 2009 to 2016 . The disputes included cases of minor and temporary disabilities that occurred due to epidural procedures or nerve blocks for chronic pain treatment, inadvertent needle-stick organ injuries, and fatalities that arose due to pulmonary embolism. In the field of anesthesiology, the area of pain management has developed rapidly and the increase in invasive procedures has brought about an increase in medical disputes.

Therefore, physicians should explain fully and clearly to patients and their families the potential complications, expectations, and side effects and other inevitable situations, even though it is the most important thing to avoid these unfortunate possibilities coming after medical practice. It cannot be emphasized enough that complete informed consent should be collected from the patients and their families, not only to reduce legal disputes and protect physicians and other medical personnel but also to secure the patients' safety.

\section{Reference}

1. Lee JY, Kim DK, Jung DW, Yang JY, Kim DY. Analysis of medical disputes regarding chronic pain management in the 2009-2016 period using the Korean Society of Anesthesiologists database. Korean J Anesthesiol 2017; 70: 188-95.

Corresponding author: Heezoo Kim, M.D., Ph.D.

Department of Anesthesiology and Pain Medicine, Korea University Guro Hospital, Korea University College of Medicine, 148, Gurodong-ro, Guro-gu, Seoul 08308, Korea

Tel: 82-2-2626-1437, Fax: 82-2-2626-1438, Email: kimheezoo@gmail.com

ORCID: http://orcid.org/0000-0002-4754-9776

Korean J Anesthesiol 2017 April 70(2): 115

https://doi.org/10.4097/kjae.2017.70.2.115

(c) This is an open-access article distributed under the terms of the Creative Commons Attribution Non-Commercial License (http://creativecommons.org/ licenses/by-nc/4.0/), which permits unrestricted non-commercial use, distribution, and reproduction in any medium, provided the original work is properly cited. 